Article

\title{
Enhanced Artificial Neural Network with Harris Hawks Optimization for Predicting Scour Depth Downstream of Ski-Jump Spillway
}

\author{
Saad Sh. Sammen 1,*(D), Mohammad Ali Ghorbani ${ }^{2}$, Anurag Malik ${ }^{3, *}$, Yazid Tikhamarine ${ }^{4}$, \\ Mohammad AmirRahmani ${ }^{5}$ D , Nadhir Al-Ansari ${ }^{6}(\mathbb{D})$ and Kwok-Wing Chau ${ }^{7}(\mathbb{D})$ \\ 1 Department of Civil Engineering, College of Engineering, University of Diyala, Diyala \\ Governorate 32001, Iraq \\ 2 Department of Civil Engineering, Istanbul Technical University, Ayazaga campus, Maslak, \\ 34469 Istanbul, Turkey; m_ali_ghorbani@ymail.com \\ 3 Regional Research Station, Punjab Agricultural University, Bathinda 151001, Punjab, India \\ 4 Leghyd Laboratory, Department of Civil Engineering, University of Sciences and Technology Houari \\ Boumediene, BP 32, Bab Ezzouar 16111, Algiers, Algeria; ytikhamarine@usthb.dz \\ 5 Institute of Environment, University of Tabriz, Tabriz 51368, Iran; m.amirrahmani@gmail.com \\ 6 Civil, Environmental and Natural Resources Engineering, Lulea University of Technology, \\ 97187 Lulea, Sweden; nadhir.alansari@ltu.se \\ 7 Department of Civil and Environmental Engineering, Hong Kong Polytechnic University, \\ Hong Kong, China; cekwchau@polyu.edu.hk \\ * Correspondence: saad123engineer@yahoo.com (S.S.S.); amalik19@pau.edu (A.M.)
}

Received: 6 June 2020; Accepted: 16 July 2020; Published: 27 July 2020

\begin{abstract}
A spillway is a structure used to regulate the discharge flowing from hydraulic structures such as a dam. It also helps to dissipate the excess energy of water through the still basins. Therefore, it has a significant effect on the safety of the dam. One of the most serious problems that may be happening below the spillway is bed scouring, which leads to soil erosion and spillway failure. This will happen due to the high flow velocity on the spillway. In this study, an alternative to the conventional methods was employed to predict scour depth (SD) downstream of the ski-jump spillway. A novel optimization algorithm, namely, Harris hawks optimization (HHO), was proposed to enhance the performance of an artificial neural network (ANN) to predict the SD. The performance of the new hybrid ANN-HHO model was compared with two hybrid models, namely, the particle swarm optimization with ANN (ANN-PSO) model and the genetic algorithm with ANN (ANN-GA) model to illustrate the efficiency of ANN-HHO. Additionally, the results of the three hybrid models were compared with the traditional ANN and the empirical Wu model (WM) through performance metrics, viz., mean absolute error (MAE), root mean square error (RMSE), coefficient of correlation (CC), Willmott index (WI), mean absolute percentage error (MAPE), and through graphical interpretation (line, scatter, and box plots, and Taylor diagram). Results of the analysis revealed that the ANN-HHO model (MAE $=0.1760 \mathrm{~m}, \mathrm{RMSE}=0.2538 \mathrm{~m}$ ) outperformed ANN-PSO $(\mathrm{MAE}=0.2094 \mathrm{~m}, \mathrm{RMSE}=0.2891 \mathrm{~m})$, ANN-GA $(\mathrm{MAE}=0.2178 \mathrm{~m}, \mathrm{RMSE}=0.2981 \mathrm{~m})$, ANN $(M A E=0.2494 \mathrm{~m}, \mathrm{RMSE}=0.3152 \mathrm{~m})$ and $\mathrm{WM}(\mathrm{MAE}=0.1868 \mathrm{~m}, \mathrm{RMSE}=0.2701 \mathrm{~m})$ models in the testing period. Besides, graphical inspection displays better accuracy of the ANN-HHO model than ANN-PSO, ANN-GA, ANN, and WM models for prediction of SD around the ski-jump spillway.
\end{abstract}

Keywords: artificial neural networks; genetic algorithm; particle swarm optimization; harris hawks optimization; scour depth; ski-jump spillway 


\section{Introduction}

Dams are among the superstructures that require very precise studies to explore every part of them from many aspects of safety, performance, and environment. The main part of these structures is their spillway, which enables operators to dispose of excess inflows to reservoirs in a controlled or uncontrolled manner. When water with high velocity is passing through the spillway, it should be designed with energy dissipaters downstream. Ski jumps taking away water from the bucket and into the air in the form of a water jet are among widely used energy dissipaters in spillways. At the outlet of these spillways where water jets to the riverbed, a plunge pool is formed due to the energy of the high-velocity water, which is often capable of excavating holes into even hard rocks and soil. In order to prevent any possible erosion and to control the stability of the dam body and other structures accurately, and to have a safe design facing the dynamic process of this phenomena, precise prediction of this scouring is critical.

Physical hydraulic models and mathematical simulation are among practices employed in studying hydraulic related phenomena including erosion and scour. Being time and cost-inefficient, physical hydraulic models are merely employed in the final phases of studies. In addition, the reliability of these models is still questionable [1]. With advances in computer science, computational fluid dynamics (CFD) methods have been broadly used in these studies [2]. However, complexities and computational limitations are still drawbacks of these methods. Therefore, researchers are still investigating an easy and immediate technique for initial estimates of scour in the feasibility study phase.

In this regard, due to the growing interest in using soft computing practices recently in several disciplines [3], researchers used these techniques to estimate scour depth for different hydraulic structures [1,4-13]. Artificial neural networks (ANN) is a branch of artificial intelligence (AI), which are capable of perceiving complex nonlinear behavior of phenomena [6]. This approach, which is inspired by human brains' functions, is employed in prediction studies of several hydraulic parameters [14-20]. Moreover, it has been used in the estimation of equilibrium bridge pier scour effectively [21,22]. Recently, Sharafati et al. [23] predicted scour depth downstream of weirs by employing the adaptive neuro-fuzzy inference system (ANFIS) coupled with biogeography based optimization (ANFIS-BBO), invasive weed optimization (ANFIS-IWO) and teaching-learning based optimization (ANFIS-TLBO) algorithms. They found better performance with the ANFIS-IWO model (RMSE $=0.148$ ) over the other models. Table 1 summarizes a brief review of the application of soft computing techniques in hydraulic structures studies.

Due to uncertainties in soft computing modeling techniques, including the topology of the network and training algorithms, scientists have employed a broad range of techniques to improve the performance of these approaches. Applying different optimization tools has been among these solutions. To this end, ANNs and then other standalone intelligent models were combined with evolutionary algorithms such as genetic algorithms (GA) or particle swarm optimization (PSO) as optimization tools by numerous researchers to estimate scour depth at bridge piers [24]. Varaki et al. [25] evaluated the ability of a hybrid intelligent model (ANFIS-GA) in the estimation of scour depth around inclined bridge piers. Karkheiran et al. [26] developed two hybrid models, namely, ANN-APSO and ANN-GA, to predict scour depth at bridge piers and concluded that the models were more reliable in terms of precision and time consumption. Sreedhara and Mandal [27] developed a hybrid swarm intelligence-based support vector machine (PSO-SVM) method for the prediction of scour depth around bridge pier with different kernel functions. It was found that PSO-SVM with the radial basis function (RBF) kernel function model was more reliable in predicting scour depth around bridge piers. Dang et al. [28] applied hybrid models of particle swarm optimization (PSO) and firefly algorithms (FFA) with ANN to optimize the parameters of the ANN model to improve estimating the pier scour depth. The results of these hybrid models were compared with the results of the standalone ANN model trained by the Levenberg-Marquardt (LM) algorithm and with an empirical formula. Results showed a better performance of the developed hybrid models. 
In a related context, recently intense application of soft computing techniques (simple and hybrid) has been found in civil engineering for modeling various aspects such as prediction of safety factor values of retaining walls [29], prediction of the critical buckling load of structural members under compression [30], estimation of surface treatment effects on the tribological performance of steel tools [31], modeling the Marshall stability of stone matrix asphalt materials [32], estimation of soil compression coefficient [33], rock tensile strength prediction [34], and forecasting pile settlement [35].

This study employs a novel hybrid optimization tool, namely, Harris hawks optimization (HHO) algorithm, for finding the most appropriate parameters of an ANN model for estimating scour depth downstream of a ski-jump spillway. To the best knowledge of the authors, there is no literature on the application of this hybrid ANN-HHO model in hydraulics and especially for the prediction of scouring depth downstream of hydraulic structures. The hybrid ANN-HHO model was employed in some cases in other disciplines such as Moayedi et al. [36] used ANN-HHO in predicting the soil compression coefficient and Essa et al. [37] applied it in a prediction of the productivity of distilling systems. Therefore, in the present research, three hybrid intelligent models ANN-HHO, ANN-PSO, and ANN-GA with the standalone ANN technique, and the Wu model were employed to predict scour depth downstream of a ski-jump spillway. The effectiveness of these models during training and testing was evaluated using five performance metrics (i.e., mean absolute error: MAE, root mean square error: RMSE, coefficient of correlation: CC, Willmott index: WI, and mean absolute percentage error: MAPE) and graphical interpretation (line, scatter, and box plots, and Taylor diagram). 
Table 1. Review of application of soft computing techniques in hydraulic structures studies.

\begin{tabular}{|c|c|c|c|c|c|c|c|c|}
\hline \multirow[b]{2}{*}{ Scholar(s) } & \multicolumn{7}{|c|}{ Soft Computing Techniques } & \multirow[b]{2}{*}{ Highlight } \\
\hline & Regression & $\begin{array}{c}\text { Genetic } \\
\text { Programming } \\
\text { (GP) }\end{array}$ & Neuro-Fuzzy & ANN & ANN-GA & ANN-PSO & $\begin{array}{l}\text { Other } \\
\text { Techniques }\end{array}$ & \\
\hline Azamathullah et al. [38] & & $\times$ & & $\times$ & & & & GP models are more accurate than ANN \\
\hline Bateni et al. [21] & & & $\times$ & $\times$ & & & & $\begin{array}{l}\text { Multilayer perception with back-propagation algorithm } \\
\text { (MLP/BP) provides better prediction than ANFIS }\end{array}$ \\
\hline Muzzammil [6] & $x$ & & & $x$ & & & & $\begin{array}{l}\text { ANN has been found better than the conventional } \\
\text { regression models }\end{array}$ \\
\hline Guven et al. [12] & $x$ & $x$ & $\times$ & & & & & $\begin{array}{l}\text { Linear genetic programming (LGP) models were } \\
\text { observed to be quite better than ANFIS and } \\
\text { regression-based equation }\end{array}$ \\
\hline Adarsh [13] & & $x$ & & $x$ & & & $x$ & $\begin{array}{l}\text { GP shows remarkably good performance in capturing } \\
\text { nonlinear relationship between the predictors and } \\
\text { predictands }\end{array}$ \\
\hline Bonakdari et al. [5] & & & & $\times$ & $x$ & & & $\begin{array}{l}\text { GA was a little better than back-error propagation (BEP) } \\
\text { technique }\end{array}$ \\
\hline Azamathullah et al. [24] & & $\times$ & & $\times$ & & & & $\begin{array}{l}\text { The performance of GP was found more effective when } \\
\text { compared to regression equations and ANNs }\end{array}$ \\
\hline Emamgholizadeh [19] & & & & $x$ & & & & $\begin{array}{l}\text { The results of this research indicate that the } \\
\text { MLP/BP model can predict the scour cone volume and } \\
\text { length efficiently }\end{array}$ \\
\hline Tahershamsi et al. [17] & & & & $\times$ & & & & $\begin{array}{l}\text { Results show that the neural network can adequately } \\
\text { estimate and MLP with one hidden layer and eight } \\
\text { hidden neurons was selected as the optimum network to } \\
\text { predict the regime width }\end{array}$ \\
\hline Onen [18] & $x$ & $x$ & & $\times$ & & & & $\begin{array}{c}\text { The performance of GEP was found in slightly more } \\
\text { influential than the ANN approach and multiple } \\
\text { nonlinear regression (MNLR) }\end{array}$ \\
\hline Najafzadeh and Azamathulla [22] & & & & $\times$ & & $x$ & $x$ & $\begin{array}{l}\text { Application of evolutionary algorithms was used } \\
\text { successfully as powerful soft computing tools as the } \\
\text { other artificial intelligence methods }\end{array}$ \\
\hline
\end{tabular}


Table 1. Cont

\begin{tabular}{|c|c|c|c|c|c|c|c|c|}
\hline \multirow[b]{2}{*}{ Scholar(s) } & \multicolumn{7}{|c|}{ Soft Computing Techniques } & \multirow[b]{2}{*}{ Highlight } \\
\hline & Regression & $\begin{array}{c}\text { Genetic } \\
\text { Programming } \\
\text { (GP) }\end{array}$ & Neuro-Fuzzy & ANN & ANN-GA & ANN-PSO & $\begin{array}{l}\text { Other } \\
\text { Techniques }\end{array}$ & \\
\hline Najafzadeh et al. [10] & & $\times$ & & & & & $x$ & Model tree approach yielded the most precise predictions \\
\hline Noori et al. [11] & $x$ & & & & & & & $\begin{array}{l}\text { Multiple linear regression (MLR) results were also } \\
\text { superior to those of well-known empirical equations }\end{array}$ \\
\hline Pourzangbar et al. [15] & & $x$ & & $x$ & & & & $\begin{array}{l}\text { The results indicated that both the GP and ANNs models } \\
\text { functioned significantly better than the existing empirical } \\
\text { formulas. Furthermore, the capability of GP was used to } \\
\text { produce meaningful mathematical rules }\end{array}$ \\
\hline Varaki et al. [25] & & & & & $x$ & & $x$ & $\begin{array}{l}\text { Comparison of results indicated that optimization of } \\
\text { ANFIS parameters improved the accuracy of prediction }\end{array}$ \\
\hline Parsaie et al. [9] & & & $x$ & $x$ & & & $x$ & $\begin{array}{l}\text { Comparing the accuracy of SVM with ANN and SVM } \\
\text { showed that the accuracy of SVM was a bit better than } \\
\text { ANN }\end{array}$ \\
\hline Karkheiran et al. [26] & & & & & $x$ & $x$ & & $\begin{array}{l}\text { It can be seen that the ANN-GA algorithm has the best } \\
\text { fitness values compared to those of the ANN-APSO } \\
\text { algorithm }\end{array}$ \\
\hline Zounemat-Kermani et al. [39] & & & $x$ & $x$ & & & & $\begin{array}{l}\text { Numerical tests indicate that feed-forward } \\
\text { backpropagation (FFBP) model provides better prediction }\end{array}$ \\
\hline
\end{tabular}




\section{Materials and Methods}

\subsection{Data Collection}

Estimating scour depth downstream of ski-jump bucket spillways has been studied in hydraulics laboratories over previous years. The Veronese formula, which suggests scouring as Equation (1), has been most widely used in scouring studies of these spillways [40]:

$$
d s=1.90 H_{1}^{0.225} q^{0.54}
$$

where, $d s$ represent the vertical depth of scour below tailwater $(\mathrm{m}), H_{1}$ shows the effective energy of jet in tailwater $(\mathrm{m})$, and $q$ denotes the specific discharge passing through the spillway $\left(\mathrm{m}^{3} / \mathrm{sec} / \mathrm{m}\right)$. Besides, $\mathrm{Wu}$ [41] suggested Equation (2) and Martins [42] proposed Equation (3) for estimating relative scour in ski-jump spillways:

$$
S D=2.11\left(\frac{q}{\sqrt{q H_{1}^{3}}}\right)^{0.51}
$$

where, $\mathrm{SD}=\left(\frac{d_{S}}{H_{1}}\right)$

$$
d s=1.5 q^{0.6} H_{1}^{0.1}
$$

\subsection{Case Study}

Experimental work conducted by previous studies was considered as a case study in this research. Therefore, data collected by Azamathulla et al. [38] were employed to study selected algorithms and their performance in SD estimation. In this study, scour depth (m) is taken as dependent variable and $\left(\frac{q}{g H_{1}^{3}}\right)$ as independent variable of the ANN network. The data set of Azamathulla et al. [38] includes 82 experiment data, in which 68 numbers were selected as the training data set and the other 14 were for testing the network's performance. Figure 1 shows the cross-sectional view of ski-jump spillway scour adopted by Azamathulla et al. [38]. In Figure 1, $q$ is the discharge intensity, $\mathrm{H}_{1}$ height of fall, $\mathrm{R}$ is the radius of the bucket, $\phi$ is the angle of bucket lip, $d_{s}$ represent the vertical depth of scouring, T.W.L is tailwater level, $\mathrm{d}_{\mathrm{w}}$ is downstream water depth, and G.L. is the ground level. Table 2 presents the statistical parameters of the dataset used in this study.

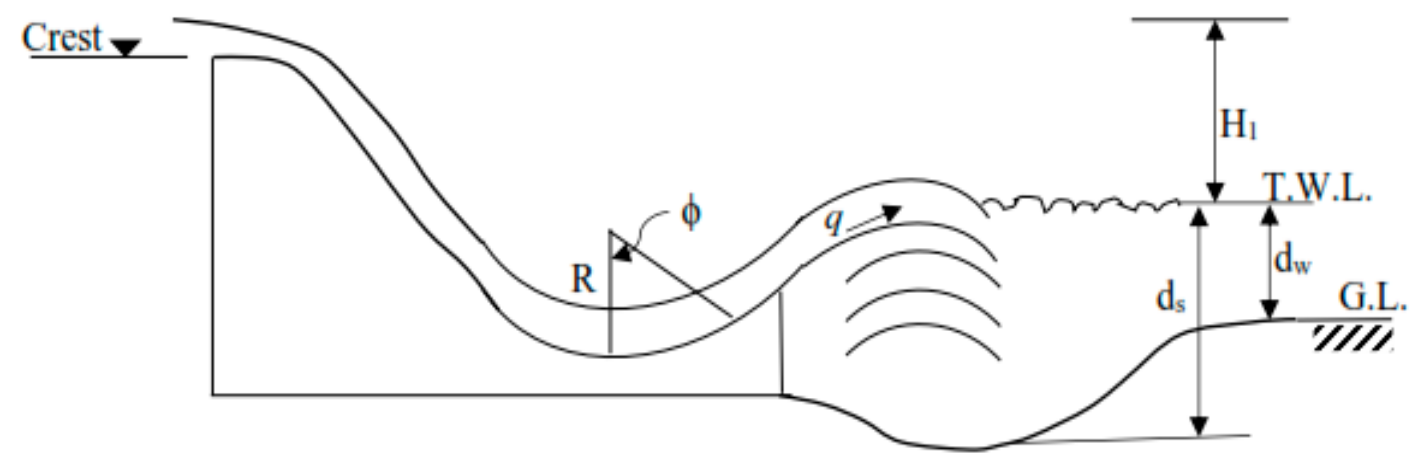

Figure 1. A schematic cross-sectional view of ski-jump spillway scour. 
Table 2. Statistical parameters of data.

\begin{tabular}{ccccccc}
\hline & Dataset & Mean & Maximum & Minimum & $\begin{array}{c}\text { Standard } \\
\text { Deviation }\end{array}$ & $\begin{array}{c}\text { Coefficient } \\
\text { of Variation }\end{array}$ \\
\hline Inputs & Total & 0.1669 & 4.4699 & 0.0040 & 0.5208 & 3.1208 \\
$\left(\frac{q}{g H_{1}^{3}}\right)$ & Training & 0.1869 & 4.4699 & 0.0040 & 0.5700 & 3.0496 \\
& Testing & 0.0696 & 0.1850 & 0.0088 & 0.0562 & 0.8073 \\
\hline \multirow{2}{*}{ Output } & Total & 0.7146 & 6.3500 & 0.0572 & 0.8318 & 1.1641 \\
$(\mathrm{SD})$ & Training & 0.7315 & 6.3500 & 0.0572 & 0.8986 & 1.2285 \\
& Testing & 0.6323 & 1.2936 & 0.1687 & 0.3747 & 0.5925 \\
\hline
\end{tabular}

Note: $g$ acceleration due to gravity $\left(\mathrm{m} / \mathrm{sec}^{2}\right)$.

\subsection{Artificial Neural Network (ANN)}

ANN is a technique, which provides a black-box model and could be used to solve different complex problems [43]. Its network topologies and training algorithms have been discussed and reviewed broadly by many scientists. Multilayer perceptron (MLP) neural networks with the Levenberg-Marquardt algorithm (LMA), which is an efficient gradient-based network training method [44], were used in this study. ANN was used to capture the relationship between the inputs and output without any details about the internal process. The main concept of ANNs to handle the data is inspired by biological nervous systems for information processing [45]. ANNs consist of an uncounted number of neurons that have interconnected together to solve different problems (Figure 2).

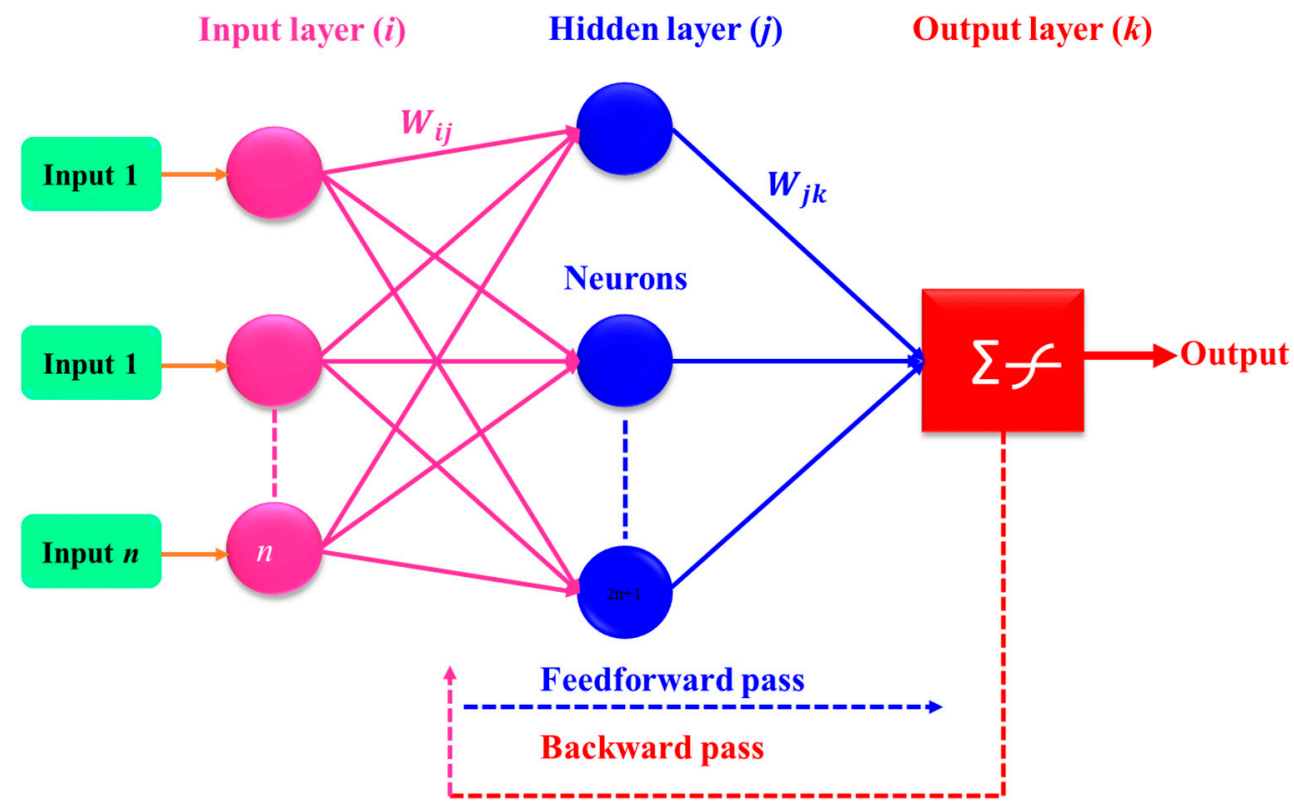

Figure 2. Structure of the artificial neural network (ANN) model.

The common structure of any neural network system consists of three layers. These layers are known as the input, hidden, and output layers. Several studies proved that the ANN of one hidden layer could estimate the relationship of complex nonlinear function with acceptable accuracy $[46,47]$. It is likewise proposed that the furthest point for the numbers of neurons in the hidden layer be lesser than $2 n+1$, where $n$ is the input neurons number [48].

\subsection{ANN-Particle Swarm Optimization (ANN-PSO) Model}

PSO is a computational population-based method inspired by the social behavior of swarms in their search space built on their own and neighbors' past successful experiments. In PSO terminology, swarm members are called "particles", each one indicating a possible solution [49]. The immediate aim 
of particles in this algorithm is to find a better position in the search space based on past experiences of flights they and their neighbors have had, to change their location and update their velocity.

In this algorithm, $X_{i}=\left(x_{i 1}, x_{i 2}, \ldots, x_{i D}\right)$ represent particles, and the situation of these particles with best-fitting function is shown as the best current position, which is $P_{i}=\left(p_{i 1}, p_{i 2}, \ldots, p_{i D}\right)$, and the corresponding fitting function is Pbest, and Gbest is known as the best general position of records $P_{g}=\left(p_{g 1}, p_{g 2}, \ldots, p_{g D}\right)$. Velocities of particles are denoted by $V_{i}=\left(v_{i 1}, v_{i 2}, \ldots, v_{i D}\right)$. Below equations demonstrate how velocity and position of particles are updated in each iteration:

$$
\begin{gathered}
V_{i d}(t+1)=\omega\left(V_{i d}(t)+c_{1} \operatorname{rand}\left(0, \varphi_{1}\right) \cdot\left(P_{i d}(t)-X_{i d}(t)\right)+c_{2} \operatorname{rand}\left(0, \varphi_{2}\right) \cdot\left(\left(P_{g d}(t)-X_{i d}(t)\right)\right)\right. \\
X_{i d}(t+1)=X_{i d}(t)+V_{i d}(t+1) \quad d=1,2, \ldots, D
\end{gathered}
$$

in which $\varphi_{1}$ and $\varphi_{2}$ are constant acceleration values. In Equation (4), rand generates a random number through the distance of its inputs, $\omega, c_{1}$ and $c_{2}$ respectively denote inertia weight, cognitive parameter, and social parameter. PSO is employed in an algorithm depicted in Figure 3a to explore the optimum weight values for the designed ANN network.

(a)

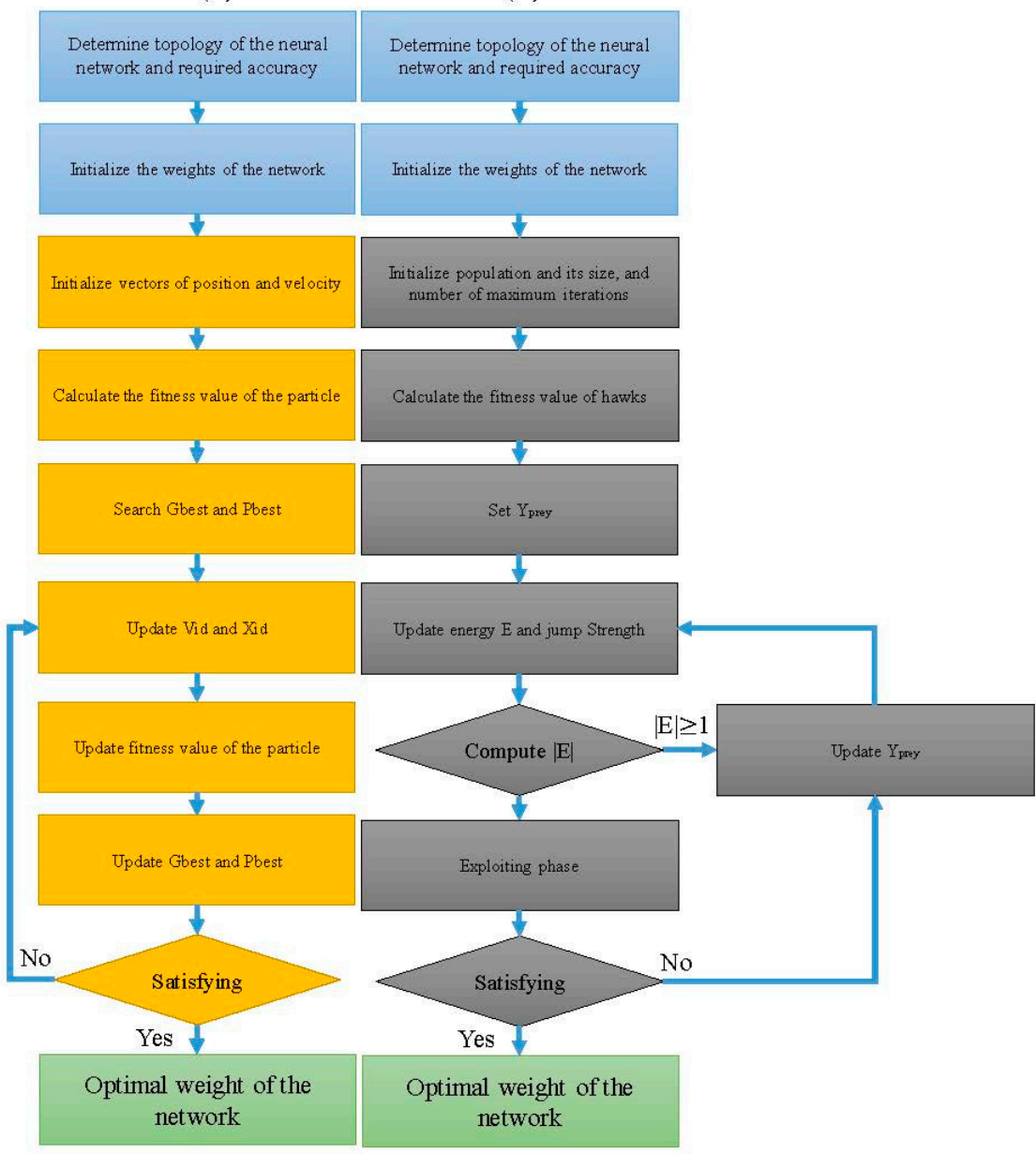

(c)

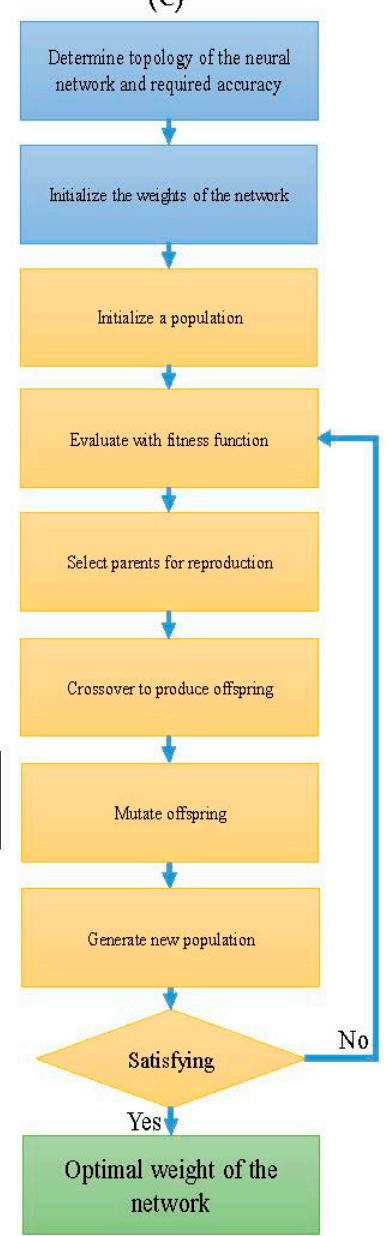

Figure 3. Flow chart of the hybrid algorithm of (a) ANN-PSO (ANN with particle swarm optimization), (b) ANN-HHO (ANN with Harris hawks optimization), and (c) ANN-GA (ANN with genetic algorithm).

\subsection{ANN-Harris Hawks Optimization (ANN-HHO) Model}

HHO is a new optimization algorithm developed by Heidari et al. [50], which employs a resemblance of Harris hawks cooperative behavior in optimization problems. In this algorithm, hawks aim to hunt the prey in three main phases of exploration, transferring, and exploiting. 
The exploration phase is consistent with waiting, seeking, and discovering possible prey. The position of hawks is located by the following equation:

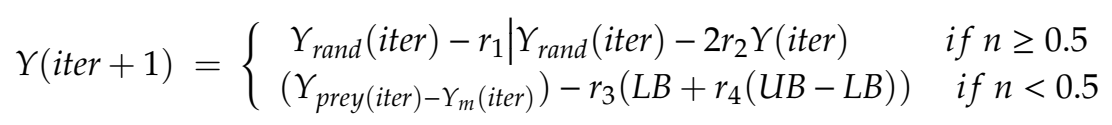

in which $Y_{\text {rand }}$ is a randomly selected existing hawk, $Y_{\text {prey }}$ denotes the prey's position, and $r_{i}(i=1,2,3,4, n)$ is a random number that ranges between 0 and 1 . The average position is represented as $Y_{m}$ and computed as follows:

$$
Y_{m}(\text { iter })=\frac{1}{N} \sum_{1}^{N} Y_{i}(\text { iter })
$$

In the transition stage, the energy of prey is modeled as $E=2 E_{0}\left(1-\frac{i t e r}{T}\right)$, in which $T$ and $E_{0}$ $\in(-1,1)$, indicating the fact that the energy of prey falls as it escapes. By computing $E$, the hawk decides whether to search for different regions or exploit the neighborhood of the solutions, in short, starting the exploration phase when $|E| \geq 1$, and exploiting the neighborhood when $|E|<1.0$. Once entering the exploiting phase, based on the value of $|E|$, hawks decide to apply a soft or hard besiege. $|E| \geq 0.5$ means the prey has enough energy to escape, but some misleading jumps result in it to fail and thus, a soft besiege works. On the other hand, when $|E|<0.5$, the prey is too fatigued to escape, so Harris' hawks hardly encircle it to finally perform the surprise pounce [50]. The flow chart of the HHO algorithm employed to optimize the ANN network is depicted in Figure 3b. For detailed information about the HHO's functioning, readers can refer to Heidari et al. [50].

\subsection{ANN-Genetic Algorithm (ANN-GA) Model}

GA is an evolutionary optimization technique inspired by Darwin's theory of natural evolution, which highlights natural selection ideas [51,52]. This notion believes the fittest individuals survive to finally reproduce offspring. GA is a heuristic method for exploring the solution space of a given problem. Primary elements of natural genetics including reproduction, crossover, and mutation are used in this algorithm.

The first step of working with optimization algorithms is selecting a proper objective function. Afterward, in GA, a population should be initialized and its fitness is tested. The next step is selecting strings to form the current population to mate, crossover, or mutate and produce a new population. The procedure of how the GA algorithm optimizes ANN parameters is graphically shown in Figure 3c.

\subsection{Performance Metrics}

The prediction accuracy of optimized ANN models (i.e., ANN-HHO, ANN-PSO, and ANN-GA) and traditional ANN and WM model for SD prediction was evaluated through mean absolute error (MAE), root mean square error (RMSE), coefficient of correlation (CC), Willmott index (WI), mean absolute percentage error (MAPE), and through graphical interpretation (line, scatter, and box plots, and Taylor diagram). The MAE, RMSE, CC, WI, and MAPE performance metrics are expressed as follows:

I. Mean absolute error $[53,54]$

$$
M A E=\frac{1}{N} \sum_{i=1}^{N}\left|S D_{p r e, i}-S D_{o b s, i}\right| \quad(0<\operatorname{MAE}<\infty)
$$

II. Root mean square error [55-57]

$$
R M S E=\sqrt{\frac{1}{N} \sum_{i=1}^{N}\left(S D_{o b s, i}-S D_{p r e, i}\right)^{2}} \quad(0<\text { RMSE }<\infty)
$$


III. Coefficient of correlation $[58,59]$

$$
C C=\frac{\sum_{\mathrm{i}=1}^{\mathrm{N}}\left(S D_{o b s, i}-\overline{S D_{o b s}}\right)\left(S D_{p r e, i}-\overline{S D_{p r e}}\right)}{\sqrt{\sum_{\mathrm{i}=1}^{\mathrm{N}}\left(S D_{o b s, i}-\overline{S D_{o b s}}\right)^{2} \sum_{\mathrm{i}=1}^{\mathrm{N}}\left(S D_{p r e, i}-\overline{S D_{p r e}}\right)^{2}}} \quad(-1<C C<1)
$$

IV. Willmott index $[60,61]$

$$
\mathrm{WI}=1-\left[\frac{\sum_{i=1}^{N}\left(S D_{p r e, i}-S D_{o b s, i}\right)^{2}}{\sum_{i=1}^{N}\left(\left|S D_{p r e, i}-\overline{S D_{o b s}}\right|+\left|S D_{o b s, i}-\overline{S D_{o b s}}\right|\right)^{2}}\right] \quad(0<\mathrm{WI} \leq 1)
$$

V. Mean absolute percentage error [61]

$$
\text { MAPE }=\frac{\sum_{i=1}^{N}\left|\frac{S D_{o b s, i}-S D_{p r e, i}}{S D_{o b s, i}}\right|}{N} \times 100 \quad(0<\text { WAPE }<\infty)
$$

where, where, $N, S D_{o b s}$, and $S D_{\text {pre }}$ are the data size, observed and predicted scour depth for the $i^{\text {th }}$ observations, $\overline{S D_{o b s}}$ and $\overline{S D_{\text {pre }}}$ are the average of observed and predicted scour depth, $\left|S D_{\text {pre }, i}-\overline{S D_{o b s}}\right|$ $=$ absolute difference between predicted and observed mean, and $\left|S D_{o b s, i}-\overline{S D_{o b s}}\right|=$ absolute difference between observed and mean of observed scour depth. By adopting the criteria of lower values of MAE, RMSE, and MAPE, and higher values of CC and WI during training and testing periods, the proposed models (i.e., ANN-HHO, ANN-PSO, and ANN-GA) and traditional ANN model are evaluated under a fair basis for scour depth prediction.

\section{Results}

\subsection{Scour Depth Prediction by Optimized ANN Models}

Three different metaheuristic algorithms (HHO, PSO, and GA) were applied to train (68 data; 83\%) and test (14 data; $17 \%$ ) an ANN for predicting scour depth around a ski-jump spillway. The controlling parameters of the $\mathrm{HHO}, \mathrm{PSO}$, and GA algorithms used in this study are listed in Table 3. Table 4 enlists values of performance metrics (MAE, RMSE, CC, WI, and MAPE) of ANN-HHO, ANN-PSO, ANN-GA, and ANN models during training and testing periods. Table 4 reveals that MAE, RMSE, CC, WI, and MAPE range from 0.1791-0.2657 m, 0.2626-0.3537 m, 0.9557-0.9197, 0.9769-0.9554, and 43.0994-80.9093\% during training for ANN-HHO, ANN-PSO, ANN-GA, and ANN models, respectively. Similarly, during testing, MAE, RMSE, CC, WI, and MAPE vary from $0.1760-0.2494 \mathrm{~m}$, 0.2538-0.3152 $\mathrm{m}, 0.7765-0.7708,0.8030-0.4597$, and 30.5081-51.3543\% for the ANN-HHO, ANN-PSO, ANN-GA, and ANN models, respectively. According to the MAE, RMSE, CC, WI and MAPE values, ANN-HHO model has better performance MAE $=0.1791 / 0.1760 \mathrm{~m}, \mathrm{RMSE}=0.2626 / 0.2538 \mathrm{~m}$, $\mathrm{CC}=0.9557 / 0.7765, \mathrm{WI}=0.9769 / 0.8030$, and MAPE $=43.0994 / 30.5081 \%$ during training/testing, respectively. Likewise, the ANN-HHO model follows the criteria of lower values of MAE, RMSE, MAPE, and higher values of CC and WI for both periods and is designated the first (or highest) rank for scour depth prediction. The ANN-PSO model closely follows the ANN-HHO model in both periods for scour depth prediction. The performance of a simple ANN and WM models was found to be the worst in scour depth prediction in this research. 
Table 3. Optimal ANN parameters using $\mathrm{HHO}$, PSO and GA algorithms.

\begin{tabular}{cc}
\hline Model & Parameters \\
\hline & $\mathrm{IW}_{1}=[1.2702 ;-4.5789 ;-2.3216]$ \\
ANN-HHO & $\left.\mathrm{b}_{1}=4.2473 ; 4.2087 ;-3.5027\right]$ \\
& $\mathrm{LW}_{2}=[-4.9710 ;-0.8578 ;-4.6376]$ \\
& $\mathrm{b} 2=[1.0285]$ \\
\hline & $\mathrm{IW}_{1}=[0.3307 ;-2.3738 ; 0.4136]$ \\
ANN-PSO & $\mathrm{b}_{1}=[2.1814 ;-2.9212 ; 0.4245]$ \\
& $\mathrm{LW}_{2}=[0.6612 ;-0.8655 ; 2.2048]$ \\
& $\mathrm{b}_{2}=[-2.0182]$ \\
\hline & $\mathrm{IW}_{1}=[1.5678 ;-2.4749 ;-0.5116]$ \\
ANN-GA & $\mathrm{b}_{1}=[1.6005 ;-2.9850 ; 1.7257]$ \\
& $\mathrm{LW}_{2}=[-1.9123 ; 0.7718 ;-1.7505]$ \\
& $\mathrm{b}_{2}=[1.1099]$ \\
\hline
\end{tabular}

Table 4. Performance metrics of hybrid and simple ANN models during training and testing.

\begin{tabular}{cccccc}
\hline \multirow{2}{*}{ Model } & \multicolumn{5}{c}{ Performance Metrics } \\
\cline { 2 - 6 } & $\begin{array}{c}\text { MAE } \\
(\mathbf{m})\end{array}$ & $\begin{array}{c}\text { RMSE } \\
\mathbf{( m )}\end{array}$ & $\mathbf{C C}$ & WI & $\begin{array}{c}\text { MAPE } \\
\mathbf{( \% )}\end{array}$ \\
\hline Training period & & & & & \\
\hline ANN-HHO & 0.1791 & 0.2626 & 0.9557 & 0.9769 & 43.0994 \\
ANN-PSO & 0.1887 & 0.2845 & 0.9491 & 0.9737 & 41.6057 \\
ANN-GA & 0.2228 & 0.3268 & 0.9308 & 0.9618 & 54.2987 \\
ANN & 0.2657 & 0.3537 & 0.9197 & 0.9554 & 80.9093 \\
\hline Testing period & & & & & \\
\hline ANN-HHO & 0.1760 & 0.2538 & 0.7765 & 0.8030 & 30.5081 \\
ANN-PSO & 0.2094 & 0.2891 & 0.7755 & 0.7323 & 32.7147 \\
ANN-GA & 0.2178 & 0.2981 & 0.7733 & 0.6544 & 37.3840 \\
ANN & 0.2494 & 0.3152 & 0.7708 & 0.4597 & 51.3543 \\
\hline
\end{tabular}

The outcomes of ANN optimized by the HHO, PSO, and GA algorithms and traditional ANN and WM models were compared over other studies conducted on SD prediction by employing the simple and hybrid machine learning models [8,24,39,62-64]. Pourzangbar et al. [15] predicted maximum scour depth at seawalls by employing GP, and ANNs models, and compared their results to empirical equations through statistical measures. They found superior outcomes of GP and ANN models over empirical equations. Parsaie et al. [65] applied support vector machine (SVM), ANN, and ANFIS models to predict scour depth below the river pipeline system. Results of the comparison showed that a better prediction was achieved by SVM models (RMSE $=0.103$ and $\mathrm{R}^{2}=0.94$ ) over the ANN and ANFIS models. Dang et al. [28] optimized ANN with PSO (ANN-PSO) and firefly algorithms (ANN-FFA) to predict scour depths around circular piers and compared them with empirical formulas and the classical ANN model trained with Levenberg-Marquardt (LM) algorithm. Results revealed better outcomes yielded by ANN-PSO and ANN-FFA models than other models (i.e., empirical formulas and classical ANN). These studies also confirmed the supremacy of soft computing techniques in SD prediction.

Figure $4 \mathrm{a}-\mathrm{d}$ to Figure $5 \mathrm{a}-\mathrm{d}$ displays the comparison among measured (observed) vs. predicted scour depths by the ANN-HHO, ANN-PSO, ANN-GA, and ANN models during training and testing periods. As noted from these figures, ANN-HHO, ANN-PSO, ANN-GA, and ANN models have coefficients of determination $\left(R^{2}\right)=0.9133,0.9099,0.8664$ and 0.8459 for training, and 0.6030, 0.6014, 0.5979 and 0.5944 for testing, respectively. Similarly, as can be seen from the figures, ANN optimized by the HHO algorithm has less scattering around the perfect line (1:1 line) than those PSO and GA algorithms as well as the standalone ANN model. Figure $6 \mathrm{a}-\mathrm{b}$ demonstrates the distribution 
of modeled (predicted) scour depth values by the ANN-HHO, ANN-PSO, ANN-GA, and ANN models over the observed values during training and testing periods through the box plot. It can be seen from Figure $6 \mathrm{a}-\mathrm{b}$ that the distributional variations among predicted vs. observed scour depth values are relatively minor. Therefore, the verdict based on performance measures (MAE, RMSE, CC, WI, and MAPE) and graphical inspection (coefficients of determination of regression line, scatter, and box plots) show a better scour depth prediction accuracy of ANN-HHO model than ANN-PSO, ANN-GA, and ANN models.

(a)

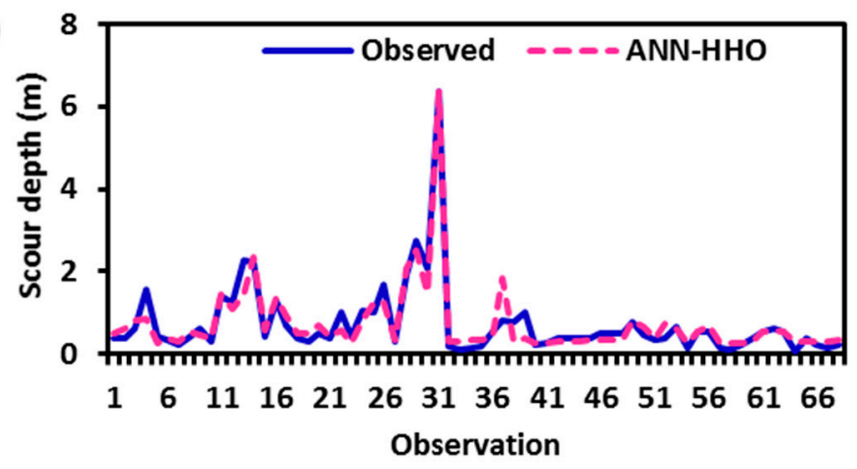

(b)

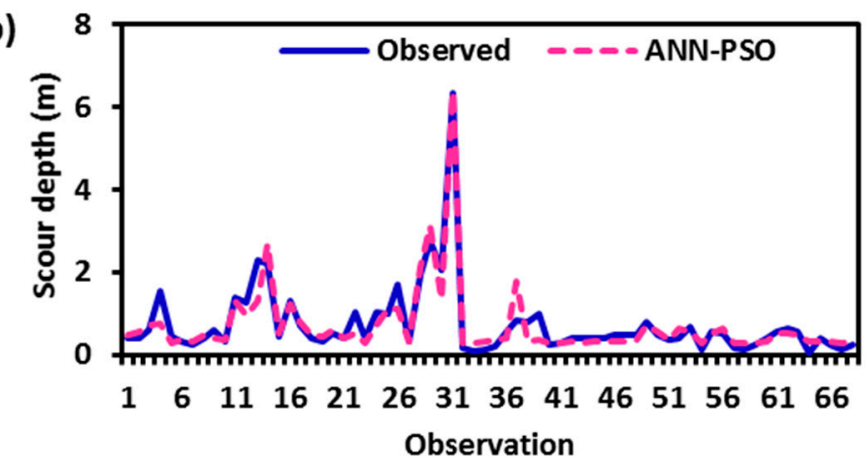

(c)

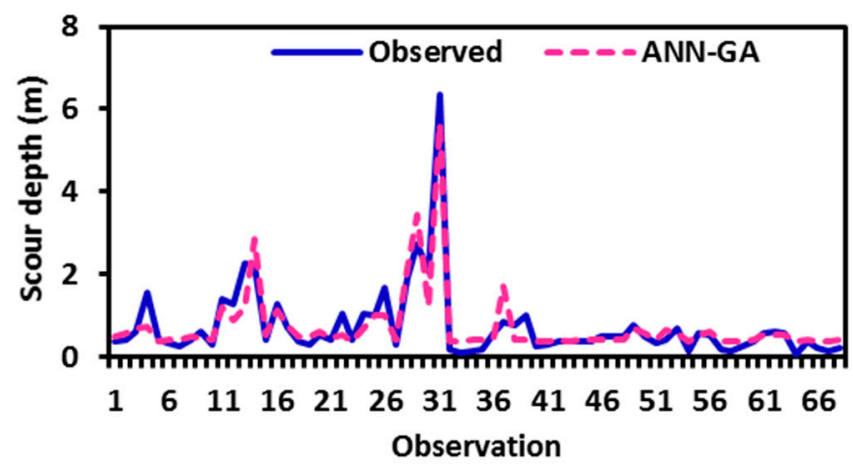

(d)

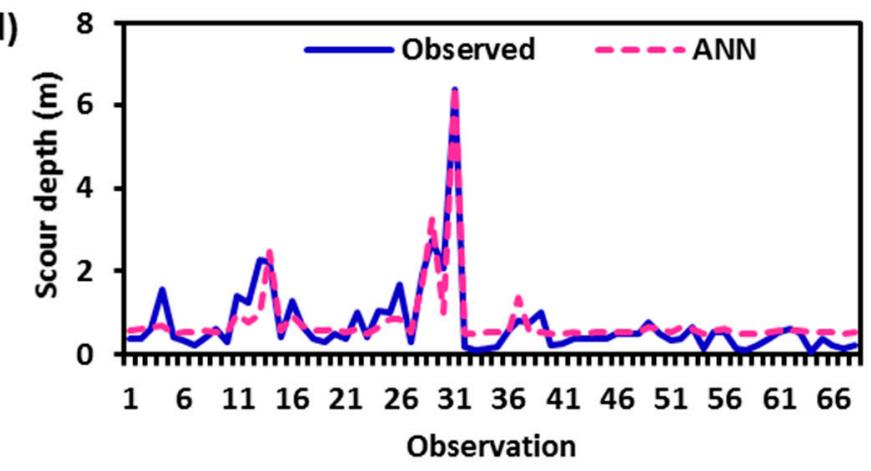

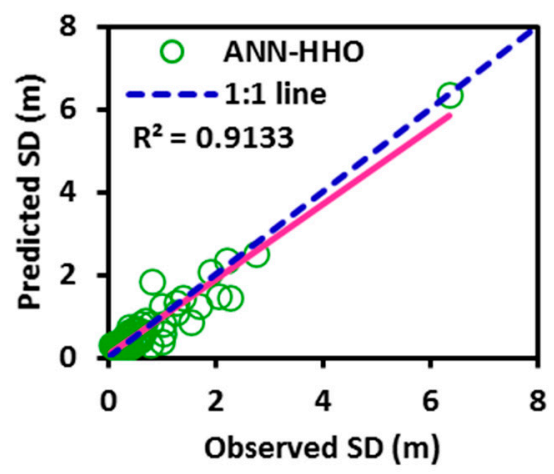
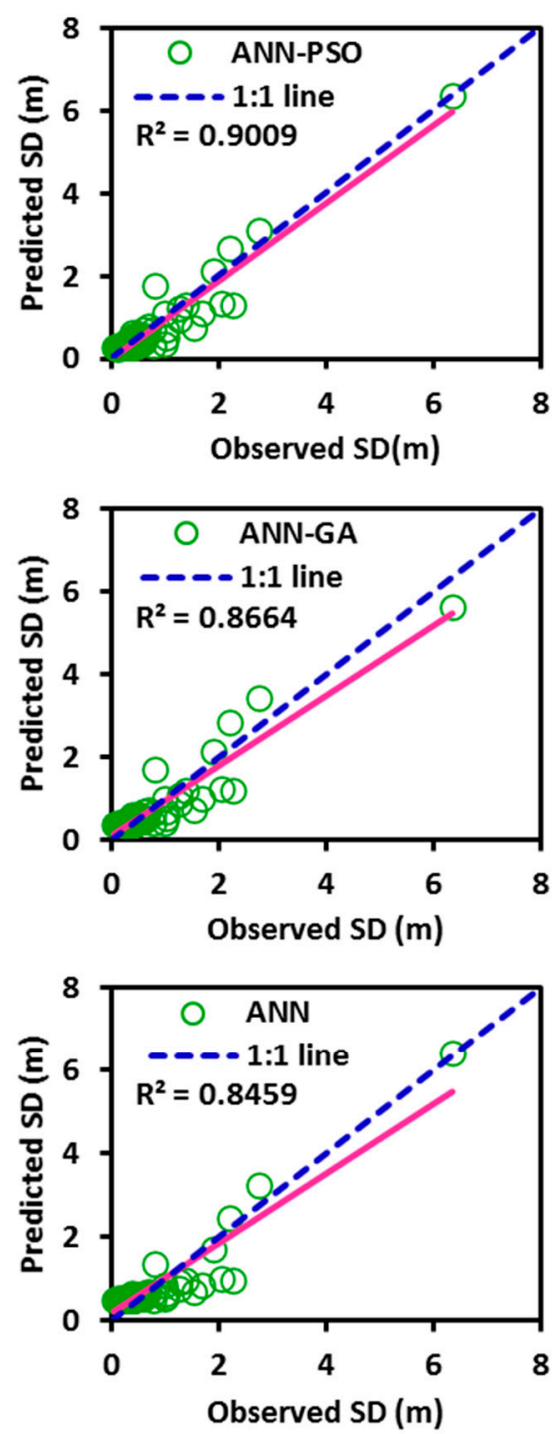

Figure 4. Line and scatter plots of (a) ANN-HHO, (b) ANN-PSO, (c) ANN-GA, and (d) ANN models during the training period. 
(a)

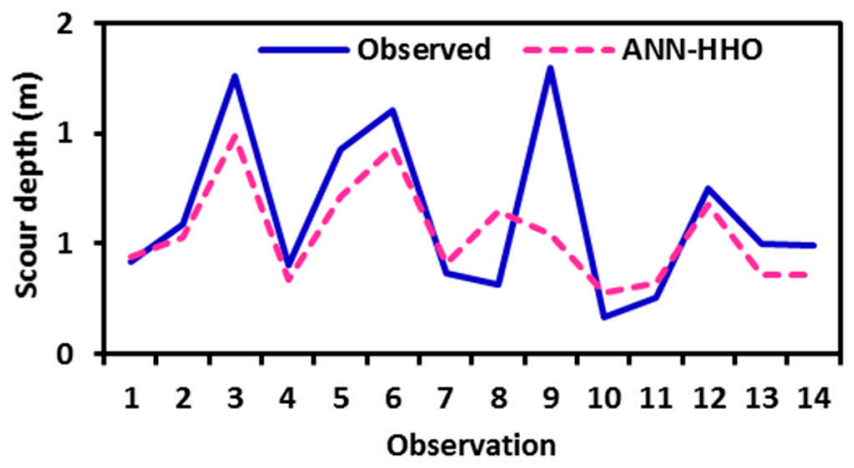

(b)

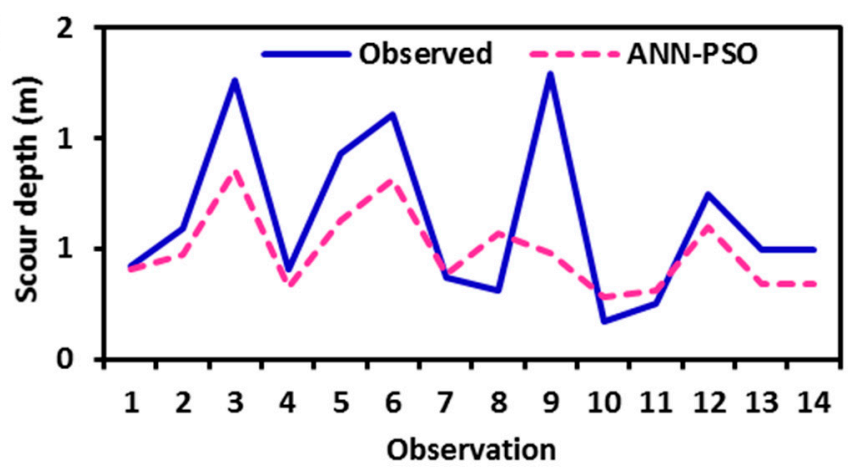

(c)

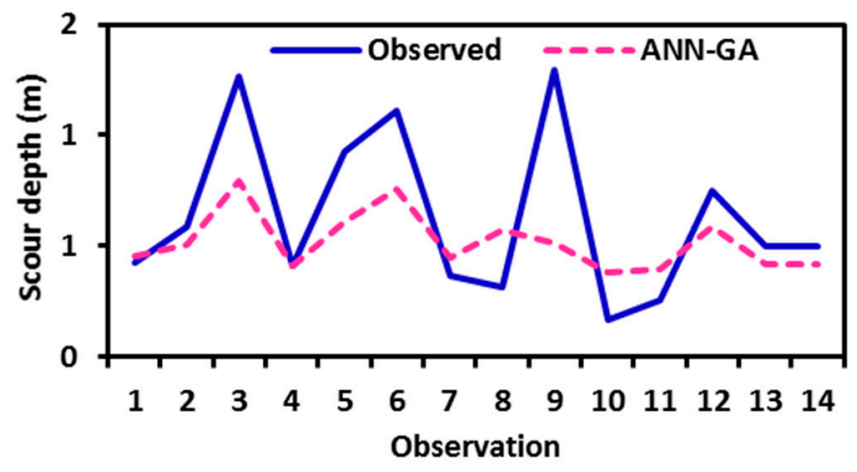

(d)

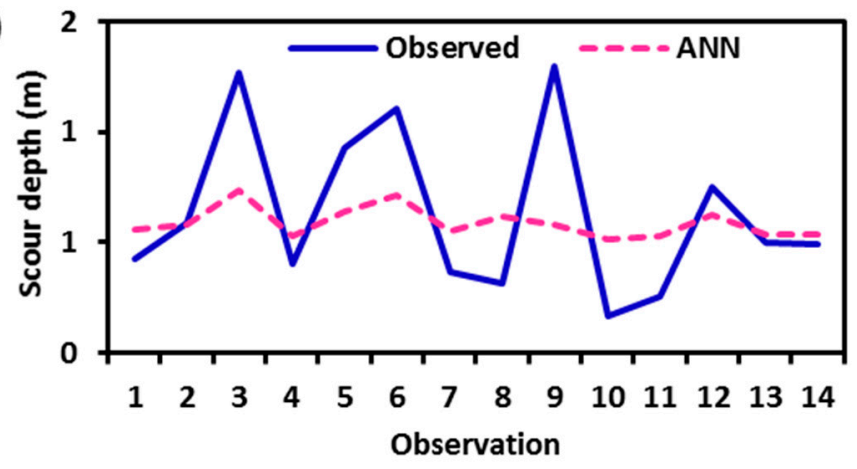

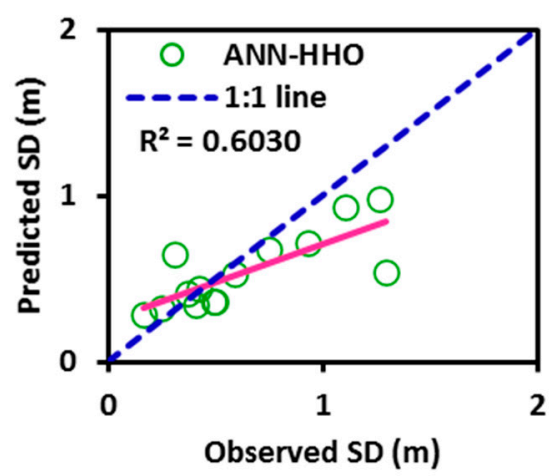
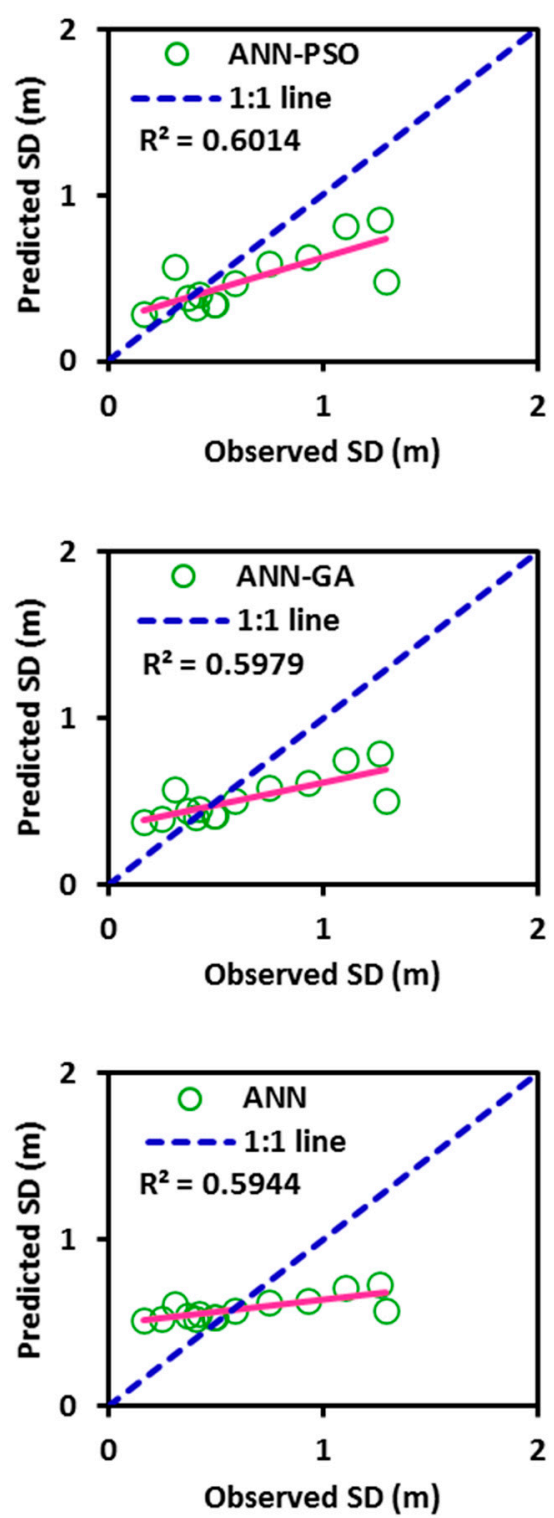

Figure 5. Line and scatter plots of (a) ANN-HHO, (b) ANN-PSO, (c) ANN-GA, and (d) ANN models during the testing period. 
(a)
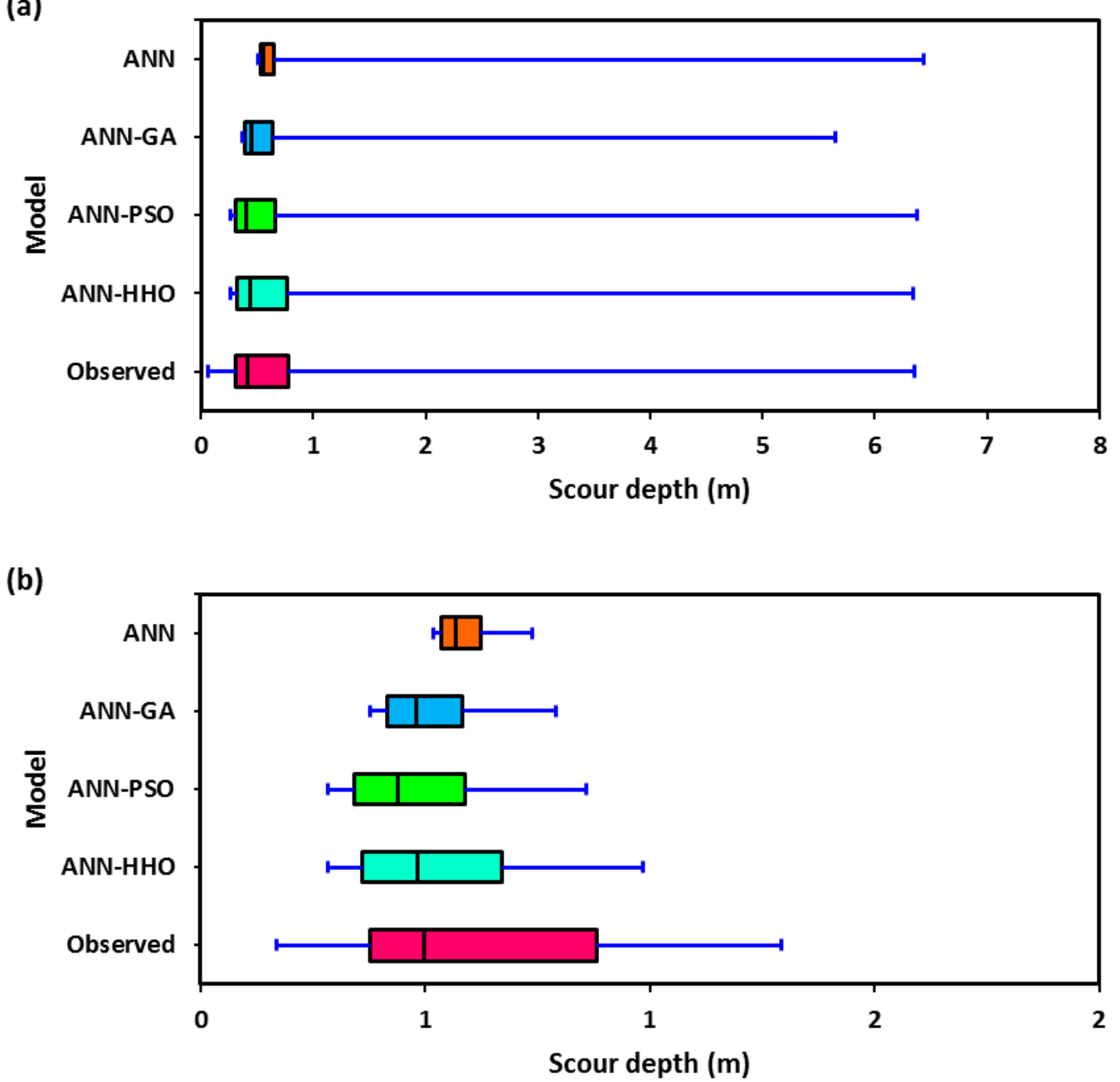

Figure 6. Box plots of observed and predicted scour depth by ANN-HHO, ANN-PSO, ANN-GA, ANN models during (a) training, and (b) testing periods.

Besides, the Taylor diagram [66], which is a consortium of standard deviation, RMSE, and the correlation coefficient, was employed to display the spatial variation of predicted scour depth by the ANN-HHO, ANN-PSO, ANN-GA, and ANN models over the observed one in single topology, as illustrated in Figure $7 \mathrm{a}, \mathrm{b}$. It can be seen from Figure 7a,b that the outcomes obtained by the ANN-HHO model are close to the observed one for SD prediction, showing superior performance of this model as discussed earlier in Table 4 and Figure $4 a-d$ to Figure $5 a-d$. 
(a)

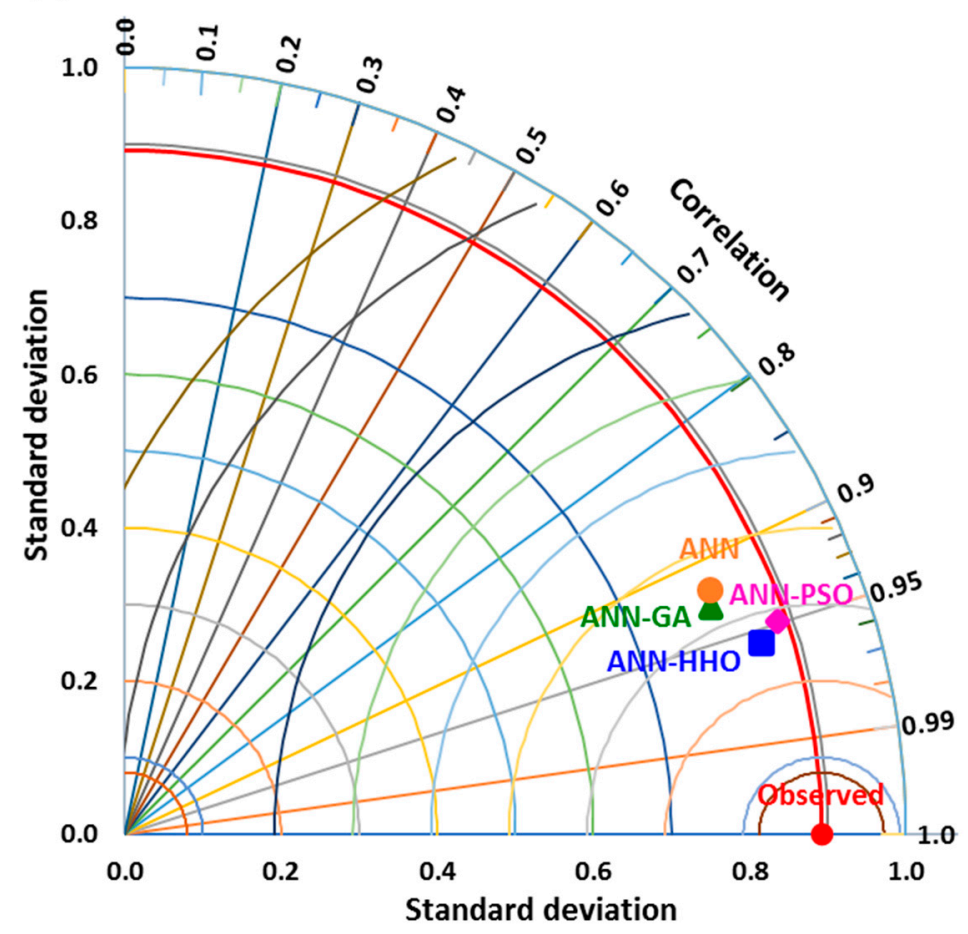

(b)

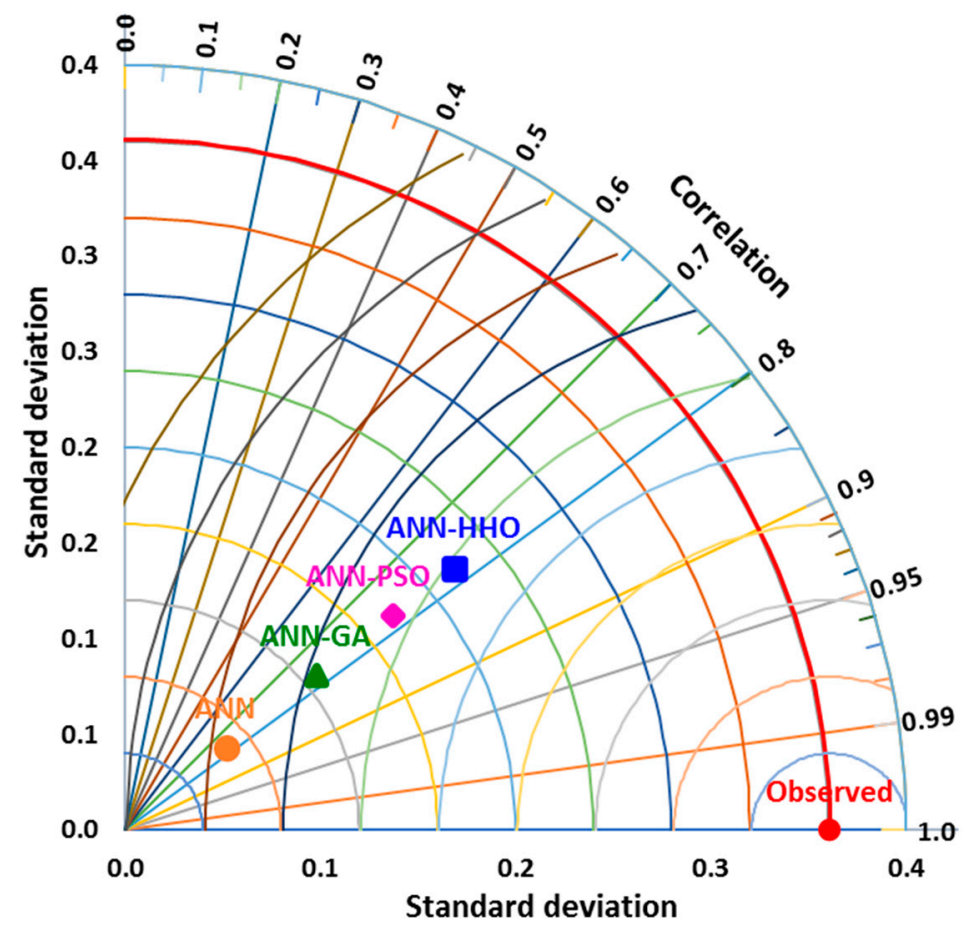

Figure 7. Taylor diagrams of ANN-HHO, ANN-PSO, ANN-GA, ANN models during (a) training, and (b) testing periods.

\subsection{Comparison and Discussion}

Accurate prediction of scour depth plays an important role in the optimal design of hydraulic structures. So, the present study employs the application of three metaheuristic algorithms (i.e., HHO, PSO, GA) integrated with ANN and traditional ANN for SD prediction around the experimental setup of the ski-jump spillway. Their accuracy was evaluated through performance metrics and 
graphical interpretation. A comparison of results reveals better feasibility, suitability, and predictability of the ANN-HHO model, closely tracked by the ANN-PSO and ANN-GA models. Additionally, the outcomes of the best ANN-HHO model were compared with the existing Wu model (Equation (2)) as shown in Table 5. It can be seen from Table 5 that the ANN-HHO model had a better prediction than the WM model for SD in terms of performance metrics. Furthermore, to validate the reliability of models, the percentage of prediction accuracy is computed using MAE/RMSE values, which reveals reductions of $5.1 \% / 19.6 \% / 32.6 \%$, and $7.7 \% / 19.6 \% / 25.8 \%$ during training and $16.0 \% / 19.2 \% / 29.4 \%$, and $12.2 \% / 14.9 \% / 19.5 \%$ during testing with ANN-HHO model over ANN-PSO, ANN-GA, and ANN models, respectively. This analysis also confirms the viability of the Harris Hawks Optimization (HHO) algorithm embedded with ANN over the Particle Swarm Optimization (PSO) and Genetic algorithm (GA) in scour depth prediction.

Table 5. Comparison of performance metrics of hybrid ANN-HHO model with Wu Model (WM).

\begin{tabular}{clllll}
\hline Model & MAE & RMSE & CC & WI & MAPE \\
\hline Training & & & & \\
\hline ANN-HHO & 0.1791 & 0.2626 & 0.9557 & 0.9769 & 43.0994 \\
\hline WM & 0.2104 & 0.3558 & 0.9480 & 0.9463 & 35.2936 \\
\hline ANN-HHO & Testing & & & & \\
\hline WM & 0.1760 & 0.2538 & 0.7765 & 0.8030 & 30.5081 \\
\hline
\end{tabular}

\section{Conclusions}

One of the objectives of spillway design is to dissipate energy at high dams in order to prevent downstream scouring. Therefore, it has a significant effect on the safety of dams. Scouring is one of the most serious problems that may happen downstream of the spillway. In this study, soft computing models are developed for the prediction of scouring depth downstream of the ski-jump spillway. The novelty of the study lies in the use of a recently developed HHO algorithm for the optimization of ANN parameters for the development of scouring depth prediction models using the experimental data collected from the previous literature. The performance of the hybrid ANN-HHO model was compared with ANN-PSO, ANN-GA, traditional ANN, and WM to display the efficacy of the newly proposed hybrid model, i.e., ANN-HHO. The performance of the ANN-HHO model was found to better in terms of all statistical metrics and graphical comparisons, where results indicate that the ANN-HHO model can predict scouring depth with the lowest value of RMSE, MAPE, and MAE and the highest CC and WI. The performance of ANN and WM was found to be poor in SD prediction. These results undoubtedly establish the efficacy of the new algorithm in the optimization of ANN model parameters and improve its prediction efficiency significantly. In the future, a study can be conducted to optimize the parameters of other AI models using the newly developed HHO algorithm for prediction of scour depth for other hydraulic structures.

Author Contributions: Conceptualization, S.S.S. and M.A.G.; methodology, Y.T. and M.A.; software, Y.T.; validation, Y.T. and M.A.; formal analysis, Y.T., A.M. and S.S.S.; investigation, S.S.S., M.A.G., A.M., N.A.-A., and K.-W.C.; writing-original draft preparation, S.S.S., M.A.G., A.M., Y.T., M.A., N.A.-A., and K.-W.C.; writing-review and editing, S.S.S., M.A.G., A.M., N.A.-A., and K.-W.C.; visualization, N.A.-A., and K.-W.C.; supervision, N.A.-A., and K.-W.C.; project administration, N.A.-A.; funding acquisition, N.A.-A. All authors have read and agreed to the published version of the manuscript.

Funding: This research received no external funding.

Conflicts of Interest: The authors declare no conflict of interest. 


\section{References}

1. Haghiabi, A.H. Estimation of scour downstream of a ski-jump bucket using the multivariate adaptive regression splines. Sci. Iran. 2017, 24, 1789-1801. [CrossRef]

2. Zhang, S.; Pang, B.; Wang, G. A new formula based on computational fluid dynamics for estimating maximum depth of scour by jets from overflow dams. J. Hydroinform. 2014, 16, 1210-1226. [CrossRef]

3. Knüsel, B.; Zumwald, M.; Baumberger, C.; Hirsch Hadorn, G.; Fischer, E.M.; Bresch, D.N.; Knutti, R. Applying big data beyond small problems in climate research. Nat. Clim. Chang. 2019, 9, 196-202. [CrossRef]

4. Azmathullah, H.M.D.; Deo, M.C.; Deolalikar, P.B. Estimation of scour below spillways using neural networks. J. Hydraul. Res. 2006, 44, 61-69. [CrossRef]

5. Bonakdari, H.; Baghalian, S.; Nazari, F.; Fazli, M. Numerical Analysis and Prediction of the Velocity Field in Curved Open Channel Using Artificial Neural Network and Genetic Algorithm. Eng. Appl. Comput. Fluid Mech. 2011, 5, 384-396. [CrossRef]

6. Muzzammil, M. Application of Neural Networks To Scour Depth Prediction at The Bridge Abutments. Eng. Appl. Comput. Fluid Mech. 2008, 2, 30-40. [CrossRef]

7. Ebtehaj, I.; Bonakdari, H. Evaluation of Sediment Transport in Sewer using Artificial Neural Network. Eng. Appl. Comput. Fluid Mech. 2013, 7, 382-392. [CrossRef]

8. Sharafati, A.; Haghbin, M.; Motta, D.; Yaseen, Z.M. The Application of Soft Computing Models and Empirical Formulations for Hydraulic Structure Scouring Depth Simulation: A Comprehensive Review, Assessment and Possible Future Research Direction. Arch. Comput. Methods Eng. 2019, 26, 1-25. [CrossRef]

9. Parsaie, A.; Haghiabi, A.H.; Saneie, M.; Torabi, H. Prediction of Energy Dissipation of Flow Over Stepped Spillways Using Data-Driven Models. Iran. J. Sci. Technol. Trans. Civ. Eng. 2018, 42, 39-53. [CrossRef]

10. Najafzadeh, M.; Tafarojnoruz, A.; Lim, S.Y. Prediction of local scour depth downstream of sluice gates using data-driven models. ISH J. Hydraul. Eng. 2017, 23, 195-202. [CrossRef]

11. Noori, R.; Sheikhian, H.; Hooshyaripor, F.; Naghikhani, A.; Adamowski, J.F.; Ghiasi, B. Granular Computing for Prediction of Scour Below Spillways. Water Resour. Manag. 2017, 31, 313-326. [CrossRef]

12. Guven, A.; Azamathulla, H.M.; Zakaria, N.A. Linear genetic programming for prediction of circular pile scour. Ocean Eng. 2009, 36, 985-991. [CrossRef]

13. Adarsh, S. Prediction of longitudinal dispersion coefficient in natural channels using soft computing techniques. Sci. Iran. 2010, 17, 363-371.

14. Abdollahpour, M.; Dalir, A.H.; Farsadizadeh, D.; Shiri, J. Assessing heuristic models through k-fold testing approach for estimating scour characteristics in environmental friendly structures. ISH J. Hydraul. Eng. 2019, 25, 239-247. [CrossRef]

15. Pourzangbar, A.; Saber, A.; Yeganeh-Bakhtiary, A.; Ahari, L.R. Predicting scour depth at seawalls using GP and ANNs. J. Hydroinform. 2017, 19, 349-363. [CrossRef]

16. Rajabi, E.; Kavianpour, M.R. Intelligent Prediction of Turbulent Flow over Backward-Facing Step using Direct Numerical Simulation Data. Eng. Appl. Comput. Fluid Mech. 2012, 6, 490-503. [CrossRef]

17. Tahershamsi, A.; Majdzade Tabatabai, M.R.; Shirkhani, R. An evaluation model of artificial neural network to predict stable width in gravel bed rivers. Int. J. Environ. Sci. Technol. 2012, 9, 333-342. [CrossRef]

18. Onen, F. Prediction of Scour at a Side-Weir with GEP, ANN and Regression Models. Arab. J. Sci. Eng. 2014, 39, 6031-6041. [CrossRef]

19. Emamgholizadeh, S. Neural network modeling of scour cone geometry around outlet in the pressure flushing. Glob. Nest J. 2012, 14, 540-549.

20. Ebtehaj, I.; Bonakdari, H. Assessment of evolutionary algorithms in predicting non-deposition sediment transport. Urban Water J. 2016, 13, 499-510. [CrossRef]

21. Bateni, S.M.; Borghei, S.M.; Jeng, D.-S. Neural network and neuro-fuzzy assessments for scour depth around bridge piers. Eng. Appl. Artif. Intell. 2007, 20, 401-414. [CrossRef]

22. Najafzadeh, M.; Azamathulla, H.M. Neuro-Fuzzy GMDH to Predict the Scour Pile Groups due to Waves. J. Comput. Civ. Eng. 2015, 29, 04014068. [CrossRef]

23. Sharafati, A.; Haghbin, M.; Haji Seyed Asadollah, S.B.; Tiwari, N.K.; Al-Ansari, N.; Yaseen, Z.M. Scouring Depth Assessment Downstream of Weirs Using Hybrid Intelligence Models. Appl. Sci. 2020, 10, 3714. [CrossRef]

24. Azamathulla, H.M.; Ghani, A.A.; Zakaria, N.A.; Guven, A. Genetic Programming to Predict Bridge Pier Scour. J. Hydraul. Eng. 2010, 136, 165-169. [CrossRef] 
25. Varaki, M.E.; Kanani, A.; Jamali, A. Prediction of scour depth around inclined bridge piers using optimized ANFIS with GA. J. Hydrosci. Environ. 2017, 1, 34-45.

26. Karkheiran, S.; Kabiri-Samani, A.; Zekri, M.; Azamathulla, H.M. Scour at bridge piers in uniform and armored beds under steady and unsteady flow conditions using ANN-APSO and ANN-GA algorithms. ISH J. Hydraul. Eng. 2019, 25, 1-9. [CrossRef]

27. Sreedhara, B.M.; Manu Mandal, S. Swarm Intelligence-Based Support Vector Machine (PSO-SVM) Approach in the Prediction of Scour Depth Around the Bridge Pier. In Advances in Intelligent Systems and Computing; Springer: Berlin/Heidelberg, Germany, 2019; pp. 455-463.

28. Dang, N.M.; Tran Anh, D.; Dang, T.D. ANN optimized by PSO and Firefly algorithms for predicting scour depths around bridge piers. Eng. Comput. 2019, 35, 1-11. [CrossRef]

29. Chen, H.; Asteris, P.G.; Armaghani, D.J.; Gordan, B.; Pham, B.T. Assessing dynamic conditions of the retaining wall: Developing two hybrid intelligent models. Appl. Sci. 2019, 9, 1042. [CrossRef]

30. Ly, H.B.; Le, L.M.; Duong, H.T.; Nguyen, T.C.; Pham, T.A.; Le, T.T.; Le, V.M.; Nguyen-Ngoc, L.; Pham, B.T. Hybrid artificial intelligence approaches for predicting critical buckling load of structural members under compression considering the influence of initial geometric imperfections. Appl. Sci. 2019, 9, 2258. [CrossRef]

31. Cavaleri, L.; Asteris, P.G.; Psyllaki, P.P.; Douvika, M.G.; Skentou, A.D.; Vaxevanidis, N.M. Prediction of surface treatment effects on the tribological performance of tool steels using artificial neural networks. Appl. Sci. 2019, 9, 2788. [CrossRef]

32. Nguyen, H.L.; Le, T.H.; Pham, C.T.; Le, T.T.; Ho, L.S.; Le, V.M.; Pham, B.T.; Ly, H.B. Development of hybrid artificial intelligence approaches and a support vector machine algorithm for predicting the marshall parameters of stone matrix asphalt. Appl. Sci. 2019, 9, 3172. [CrossRef]

33. Samui, P.; Hoang, N.D.; Nhu, V.H.; Nguyen, M.L.; Ngo, P.T.T.; Bui, D.T. A new approach of hybrid bee colony optimized neural computing to estimate the soil compression coefficient for a housing construction project. Appl. Sci. 2019, 9, 4912. [CrossRef]

34. Huang, L.; Asteris, P.G.; Koopialipoor, M.; Armaghani, D.J.; Tahir, M.M. Invasive weed optimization technique-based ANN to the prediction of rock tensile strength. Appl. Sci. 2019, 9, 5372. [CrossRef]

35. Armaghani, D.J.; Asteris, P.G.; Fatemi, S.A.; Hasanipanah, M.; Tarinejad, R.; Rashid, A.S.A.; Van Huynh, V. On the use of neuro-swarm system to forecast the pile settlement. Appl. Sci. 2020, 10, 1904. [CrossRef]

36. Moayedi, H.; Gör, M.; Lyu, Z.; Bui, D.T. Herding Behaviors of grasshopper and Harris hawk for hybridizing the neural network in predicting the soil compression coefficient. Measurement 2020, 152, 107389. [CrossRef]

37. Essa, F.A.; Abd Elaziz, M.; Elsheikh, A.H. An enhanced productivity prediction model of active solar still using artificial neural network and Harris Hawks optimizer. Appl. Therm. Eng. 2020, 170, 115020. [CrossRef]

38. Azamathulla, H.M.; Ghani, A.A.; Zakaria, N.A.; Lai, S.; Chang, C.; Leow, C.; Abuhasan, Z. Genetic programming to predict ski-jump bucket spill-way scour. J. Hydrodyn. 2008, 20, 477-484. [CrossRef]

39. Zounemat-Kermani, M.; Beheshti, A.-A.; Ataie-Ashtiani, B.; Sabbagh-Yazdi, S.-R. Estimation of current-induced scour depth around pile groups using neural network and adaptive neuro-fuzzy inference system. Appl. Soft Comput. 2009, 9, 746-755. [CrossRef]

40. Yildiz, D.; Uzucek, E. Prediction of scour depth from free falling flip bucket jets. Int. Water Power Dam Constr. 1994, 46, 50-56.

41. Wu, C. Scour at downstream end of dams in Taiwan. Int. Symp. River Mech. Bangkok Thail. 1973, 1, 1-6.

42. Martins, R.B. Scouring of rocky river beds by free jet spillways. Int. Water Power Dam Constr. 1975, 27, 152-153.

43. Dawson, C.W.; Wilby, R.L. Hydrological modelling using artificial neural networks. Prog. Phys. Geogr. Earth Environ. 2001, 25, 80-108. [CrossRef]

44. Piotrowski, A.P.; Napiorkowski, J.J. Optimizing neural networks for river flow forecasting-Evolutionary Computation methods versus the Levenberg-Marquardt approach. J. Hydrol. 2011, 407, 12-27. [CrossRef]

45. Sammen, S.S.; Mohamed, T.A.; Ghazali, A.H.; El-Shafie, A.H.; Sidek, L.M. Generalized Regression Neural Network for Prediction of Peak Outflow from Dam Breach. Water Resour. Manag. 2017, 31, 549-562. [CrossRef]

46. Malik, A.; Kumar, A.; Ghorbani, M.A.; Kashani, M.H.; Kisi, O.; Kim, S. The viability of co-active fuzzy inference system model for monthly reference evapotranspiration estimation: Case study of Uttarakhand State. Hydrol. Res. 2019, 50, 1623-1644. [CrossRef] 
47. Malik, A.; Kumar, A.; Kisi, O. Monthly pan-evaporation estimation in Indian central Himalayas using different heuristic approaches and climate based models. Comput. Electron. Agric. 2017, 143, 302-313. [CrossRef]

48. Malik, A.; Kumar, A.; Salih, S.Q.; Kim, S.; Kim, N.W.; Yaseen, Z.M.; Singh, V.P. Drought index prediction using advanced fuzzy logic model: Regional case study over Kumaon in India. PLoS ONE 2020, 15, e0233280. [CrossRef]

49. Kennedy, J.; Eberhart, R. Particle Swarm Optimization. In Proceedings of the IEEE International Conference on Neural Networks Vol. IV, Perth, Australia, 27 November-1 December 1995; pp. 1942-1948.

50. Heidari, A.A.; Mirjalili, S.; Faris, H.; Aljarah, I.; Mafarja, M.; Chen, H. Harris hawks optimization: Algorithm and applications. Futur. Gener. Comput. Syst. 2019, 97, 849-872. [CrossRef]

51. Goldberg, D.E. Genetic Algorithms in Search, Optimization, and Machine Learning; Addison-Wesley Longman Publ. Co. Inc: Boston, MA, USA, 1989; p. 372.

52. Holland, J.H. Genetic Algorithms. Sci. Am. 1992, 267, 66-73. [CrossRef]

53. Tikhamarine, Y.; Souag-Gamane, D.; Kisi, O. A new intelligent method for monthly streamflow prediction: Hybrid wavelet support vector regression based on grey wolf optimizer (WSVR-GWO). Arab. J. Geosci. 2019, 12, 540. [CrossRef]

54. Pham, Q.B.; Abba, S.I.; Usman, A.G.; Linh, N.T.T.; Gupta, V.; Malik, A.; Costache, R.; Vo, N.D.; Tri, D.Q. Potential of Hybrid Data-Intelligence Algorithms for Multi-Station Modelling of Rainfall. Water Resour. Manag. 2019, 33, 5067-5087. [CrossRef]

55. Singh, A.; Malik, A.; Kumar, A.; Kisi, O. Rainfall-Runoff modeling in hilly watershed using heuristic approaches with gamma test. Arab. J. Geosci. 2018, 11, 261. [CrossRef]

56. Malik, A.; Kumar, A.; Singh, R.P. Application of Heuristic Approaches for Prediction of Hydrological Drought Using Multi-Scalar Streamflow Drought Index. Water Resour. Manag. 2019, 33, 3985-4006. [CrossRef]

57. Tikhamarine, Y.; Malik, A.; Kumar, A.; Souag-Gamane, D.; Kisi, O. Estimation of monthly reference evapotranspiration using novel hybrid machine learning approaches. Hydrol. Sci. J. 2019, 64, 1824-1842. [CrossRef]

58. Adnan, R.M.; Malik, A.; Kumar, A.; Parmar, K.S.; Kisi, O. Pan evaporation modeling by three different neuro-fuzzy intelligent systems using climatic inputs. Arab. J. Geosci. 2019, 12, 606. [CrossRef]

59. Malik, A.; Kumar, A. Meteorological drought prediction using heuristic approaches based on effective drought index: A case study in Uttarakhand. Arab. J. Geosci. 2020, 13, 276. [CrossRef]

60. Willmott, C.J. On the validation of models. Phys. Geogr. 1981, 2, 184-194. [CrossRef]

61. Malik, A.; Kumar, A.; Kim, S.; Kashani, M.H.; Karimi, V.; Sharafati, A.; Ghorbani, M.A.; Al-Ansari, N.; Salih, S.Q.; Yaseen, Z.M.; et al. Modeling monthly pan evaporation process over the Indian central Himalayas: Application of multiple learning artificial intelligence model. Eng. Appl. Comput. Fluid Mech. 2020, 14, 323-338. [CrossRef]

62. Rashki Ghaleh Nou, M.; Azhdary Moghaddam, M.; Shafai Bajestan, M.; Azamathulla, H.M. Estimation of scour depth around submerged weirs using self-adaptive extreme learning machine. J. Hydroinform. 2019, 21, 1082-1101. [CrossRef]

63. Zahiri, A.; Azamathulla, H.M.; Ghorbani, K. Prediction of local scour depth downstream of bed sills using soft computing models. In Computational Intelligence Techniques in Earth and Environmental Sciences; Springer: Berling/Heidelberg, Germany, 2014; ISBN 9789401786423.

64. Azamathulla, H.M.; Mohd Yusoff, M.A. Soft computing for prediction of river pipeline scour depth. Neural Comput. Appl. 2013, 23, 2465-2469. [CrossRef]

65. Parsaie, A.; Haghiabi, A.H.; Moradinejad, A. Prediction of Scour Depth below River Pipeline using Support Vector Machine. KSCE J. Civ. Eng. 2019, 23, 2503-2513. [CrossRef]

66. Taylor, K.E. Summarizing multiple aspects of model performance in a single diagram. J. Geophys. Res. Atmos. 2001, 106, 7183-7192. [CrossRef]

(C) 2020 by the authors. Licensee MDPI, Basel, Switzerland. This article is an open access article distributed under the terms and conditions of the Creative Commons Attribution (CC BY) license (http://creativecommons.org/licenses/by/4.0/). 